BACKGROUnD: The preventive effect of low-dose aspirin in cardiovascular disease is generally attributed to its antiplatelet action caused by differential inhibition of platelet cyclooxygenase-1. However, there is evidence that aspirin also affects release of inflammatory cytokines, including tumor necrosis factor- $\alpha$ (TNF- $\alpha$ ). It is not known whether this is caused by direct action on the cytokine pathway or indirectly through cyclooxygenase inhibition and altered prostanoid synthesis, or both.

Methods: We assessed the capacity of lipopolysaccharide-activated leukocytes in whole blood cultures of eight healthy subjects following a single oral dose of $80 \mathrm{mg}$ aspirin to release $T N F-\alpha$, prostanoid $E_{2}$ $\left(P E_{2}\right)$ and prostanoid $I_{2}\left(P G I_{2}\right)$, and thromboxane $A_{2}$ $\left(\right.$ TXA $\left._{2}\right)$. TNF- $\alpha$ and prostanoids were determined by enzyme-linked immunoassays.

Results: In seven subjects, TNF- $\alpha$ release in blood cultures decreased $24 \mathrm{~h}$ after intake of aspirin. The effect of aspirin on prostanoid release was assessed in three individuals: $\mathbf{P G E}_{2}$ increased in all subjects, $\mathbf{P G I}_{2}$ increased in two and remained unchanged in one, and $T_{X A_{2}}$ was reduced in two and unchanged in one individual. The presence of DFU, a specific inhibitor of cyclooxygenase 2 , did not affect the reduction of TNF- $\alpha$ release by aspirin, but abolished prostanoid production in all three individuals.

Conclusion: The capacity of activated leukocytes to release TNF- $\alpha$ is reduced by ingestion of low-dose aspirin, independent of changes in prostanoid biosynthesis.

Key words: Low-dose aspirin, Tumor necrosis factor- $\alpha$, Cyclooxygenase inhibition, Prostanoids

\section{Release of tumor necrosis factor- $\alpha$ and prostanoids in whole blood cultures after in vivo exposure to low-dose aspirin}

\author{
Ilse Beckmann ${ }^{1, C A}$, Shlomo Ben-Efraim ${ }^{2}$, \\ Monica Vervoort ${ }^{1}$ and Henk C. S. Wallenburg ${ }^{1}$
}

\begin{abstract}
${ }^{1}$ Department of Obstetrics and Gynecology, Erasmus University School of Medicine and Health Sciences, P.O.B. 1738, 3000 DR Rotterdam, The Netherlands, and ${ }^{2}$ Department of Human Microbiology, Sackler School of Medicine, Tel-Aviv University, Tel Aviv, Israel
\end{abstract}

\author{
${ }^{\mathrm{CA}}$ Corresponding Author \\ Tel: +31 104087598 \\ Fax: +31 104087532 \\ E-mail: beckmann@gyno.fgg.eur.nl
}

\section{Introduction}

The demonstrated benefits of low-dose aspirin in the prevention of cardiovascular disease are generally explained by differential inhibition of the constitutive cyclooxygenase enzyme cyclooxygenase-1 (COX-1) in platelets, resulting in a reduced synthesis of vasoconstrictive and platelet aggregation stimulating thromboxane $\mathrm{A}_{2}\left(\mathrm{TXA}_{2}\right) .{ }^{1,2}$ The same mechanism is thought to be involved in the still disputed prevention of pre-eclampsia and fetal growth retardation (FGR) by low-dose aspirin. ${ }^{3-5}$ Recent studies have focused on the importance of release of inflammatory cytokines, such as tumor necrosis factor- $\alpha$ $(\mathrm{TNF}-\alpha)$, in the pathophysiology of these vascular events. $^{6-9}$ It is known that the biosynthesis and release of inflammatory cytokines by activated leukocytes are affected by prostanoid $\mathrm{E}_{2}\left(\mathrm{PGE}_{2}\right)$, prostanoid $\mathrm{I}_{2}\left(\mathrm{PGI}_{2}\right)$ and $\mathrm{TXA}_{2},{ }^{10,11}$ produced simultaneously in activated mononuclear cells through induced cyclooxygenase COX-2. Results of two studies indicate that in vivo exposure to aspirin alters the release of TNF- $\alpha$ by peripheral blood mononuclear cells, ${ }^{12,13}$ but it is not clear whether this is a direct effect caused by inhibition of the cytokine pathway, an indirect effect due to inhibition of COX1 and/or COX-2, or whether both mechanisms are involved.

Our study was designed to assess the effect of ' $i n$ vivo' exposure to a single low dose of aspirin on the release of TNF- $\alpha, \mathrm{PGE}_{2}, \mathrm{PGI}_{2}$ and $\mathrm{TXA}_{2}$ by lipopolysaccharide (LPS)-activated leukocytes in whole blood culture, and to investigate their interaction under the influence of aspirin. In some of our experiments, the effect of prostanoids TNF- $\alpha$ synthesis was eliminated by blocking the synthesis of $\mathrm{PGE}_{2}, \mathrm{PGI}_{2}$ and $\mathrm{TXA}_{2}$ in LPS-activated monocytes with DFU (5,5'-dimethyl-3-(3-fluorophenyl)-4-(4-methylsulfonyl) phenyl-2(5H)-furanone), a specific inhibitor of inducible COX-2. ${ }^{14}$ 


\section{Materials and methods}

\section{Materials}

Aspirin (acetylsalicylic acid, non-coated, $80 \mathrm{mg}$ tablets) was obtained from Pharmachemie B.V. (Haarlem, The Netherlands). DFU was kindly provided by Merck Frosst (Quebec, Canada) through the courtesy of Dr A. W. Ford-Hutchinson. TNF- $\alpha$ was obtained from Knoll (Ludwigshafen, Germany). Mouse anti-human TNF- $\alpha$ monoclonal antibody (mAb1) and biotinylated mouse anti-human TNF- $\alpha$ monoclonal antibody (mAb11) for enzyme-linked immunosorbent assay (ELISA) determinations were purchased from PharMingen (San Diego, CA, USA). Cell culture medium RPMI and supplements were obtained from Life Technologies B.V. (Breda, The Netherlands). Streptavidin-horseradish peroxide conjugate was obtained from the Central Laboratory of the Netherlands Red Cross Blood Transfusion Service (Amsterdam, The Netherlands). LPS Escherichia coli 0111 B4, bovine serum albumin (BSA), 3,3',5,5'-tetramethylbenzidine (TMB) and Tween 20 (polyoxyethylenesorbitan monolaureate) were purchased from Sigma (St. Louis, MO, USA). All other chemicals were from Merck (Darmstadt, Germany).

\section{Study subjects}

Nine healthy female, non-pregnant volunteers aged 24-35 years participated in the study. Informed consent was obtained from all subjects. Participants used oral contraceptives but no other drugs during at least 2 weeks before and during the experiments.

\section{Sampling}

Venous blood was obtained from all subjects immediately before (day 1, 8.00 a.m.) and $24 \mathrm{~h}$ after oral intake of $80 \mathrm{mg}$ aspirin (day 2). One subject ingested $80 \mathrm{mg}$ aspirin for 15 consecutive days and was sampled on days 1, 2, 9, 13 and 16. Blood samples were drawn into endotoxin-free vacutainers (BectonDickinson) with ethylenediamine tetraacetic acid as anticoagulant and processed immediately after sampling.

\section{Whole blood cultures}

Seven hundred and fifty microliters of blood were diluted 1:10 with RPMI 1640 culture medium with $25 \mathrm{mM}$ Hepes, supplemented with $100 \mathrm{U} / \mathrm{ml}$ penicillin, $100 \mu \mathrm{g} / \mathrm{ml}$ streptomycin, $4 \mathrm{mM} \mathrm{L-glutamine}$ and $10 \%$ fetal calf serum, and then incubated in the presence of LPS E. coli O111 B4 $(20 \mu \mathrm{g} / \mathrm{ml}$ full blood, dissolved in phosphate-buffered saline (PBS) ( $\mathrm{pH} 7.4$ )) for $0-48 \mathrm{~h}$ at $37^{\circ} \mathrm{C}$ and $5 \% \mathrm{CO}_{2}$. Blood cultures were sampled at $0,12,24$ and $48 \mathrm{~h}$, samples centrifuged for
$10 \mathrm{~min}$ at $1500 \times g$ and culture supernatants kept at $-80^{\circ} \mathrm{C}$ until analysis.

\section{Inbibition of COX-2 in whole blood cultures}

Seven hundred and fifty microliters of blood were diluted with RPMI 1640 culture medium as already described and incubated with $4 \mu 1$ DFU solution ( $5 \mu \mathrm{M}$ in dimethylsulfoxide (DMSO)) for $15 \mathrm{~min}$ at $37^{\circ} \mathrm{C}$ and $5 \% \mathrm{CO}_{2}$. LPS was added and blood cultures were processed as already described.

\section{Determination of TNF- $\alpha$}

TNF- $\alpha$ in blood culture supernatants was determined by an enzyme-linked immunoassay (PharMingen ELISA) using one capturing monoclonal antibody. Briefly, 96-well microtiter plates were coated overnight at $4^{\circ} \mathrm{C}$ with mAb1 (25 ng/well) in $0.1 \mathrm{M}$ $\mathrm{NaHCO}_{3}$ (pH 8.2). The plates were washed with washing buffer PBS (pH 7.4)/Tween 20 (PBS/Tween; 1000:1) and incubated for $2 \mathrm{~h}$ with a $3 \%$ (w/v) solution of BSA in PBS $(200 \mu 1 /$ well). After washing with PBS/Tween, TNF- $\alpha$ standards and samples, diluted in complete RPMI 1640 culture medium, were applied and incubated overnight at $4^{\circ} \mathrm{C}$. The microtiter plates were washed again with PBS/ Tween and incubated with biotinylated monoclonal anti-human TNF- $\alpha$ antibody mAb-11 (50 ng/well, in complete RPMI 1640 culture medium) for $45 \mathrm{~min}$ at room temperature. After washing with PBS/Tween, the plates were further incubated with peroxidaselabeled streptavidin ( $25 \mathrm{ng} /$ well in Tris-HCl buffer ( $\mathrm{pH} 8.0$ ) with $0.1 \%$ gelatine, $0.1 \%$ caseine and $0.02 \%$ Tween). After incubation for $30 \mathrm{~min}$ at room temperature and washing with PBS/Tween, $100 \mu 1 \mathrm{TMB}$ chromogene solution $(100 \mu \mathrm{g} \mathrm{TMB} / \mathrm{ml}$ sodium acetate solution ( $\mathrm{pH} 5.5$ ) with $1 \mu 1$ of $3 \% \mathrm{H}_{2} \mathrm{O}_{2}$ ) were added, incubated in the dark for $30 \mathrm{~min}$ at room temperature and the substrate reaction stopped with $1 \mathrm{M} \mathrm{H}_{2} \mathrm{SO}_{4}(100 \mu \mathrm{l} /$ well). The absorbance per well was measured at $450 \mathrm{~nm}$ with a Medgenix EASIA reader, and TNF- $\alpha$ concentrations in samples calculated using the TNF- $\alpha$ standard calibration line. Intraassay and interassay coefficients of variation were 10 and $15 \%$, respectively, and the detection limit was $10 \mathrm{pg} / \mathrm{ml}$. Results are expressed as nanograms of TNF- $\alpha$ per milliliter of blood or calculated as nanograms of TNF- $\alpha$ per $10^{5}$ monocytes in the longitudinal experiment with subject 9 . In subjects 5-7, TNF$\alpha$ concentrations in culture supernatants were also determined with a commercially available enzyme amplified sensitivity immunoassay (EASIA; BioSource Europe S.A., Fleurus, Belgium) with three monoclonal antibodies detecting different epitopes on the TNF- $\alpha$ molecule. Intra-assay and interassay coefficients of variation were 6 and $10 \%$, respectively, and the detection limit was $3 \mathrm{pg} / \mathrm{ml}$. 


\section{Purification and determination of prostanoids}

For purification of prostanoids in blood culture supernatants, a Sep-Pak $\mathrm{C}_{18}$ cartridge (Waters, Milford, MA, USA) was prewashed with $10 \mathrm{ml}$ absolute ethanol, $10 \mathrm{ml}$ distilled water, and $2 \mathrm{ml}$ air. One milliliter of culture supernatant was applied to the cartridge and the cartridge washed with $2 \mathrm{ml}$ distilled water, and the prostanoids were eluated with $1 \mathrm{ml}$ absolute ethanol, followed by $2 \mathrm{ml}$ air. The eluate was dried at $40^{\circ} \mathrm{C}$ under vacuum in a Speed-VacuumConcentrator, dissolved in assay buffer according to the instructions of the manufacturer, and analyzed.

$\mathrm{TXA}_{2}$ with a half-life of approximately $30 \mathrm{sec}$ under physiological conditions was measured as its stable metabolite $\mathrm{TXB}_{2}$, and $\mathrm{PGI}_{2}$ as its stable metabolite 6-keto-prostaglandin $\mathrm{F}_{1 \alpha}$. All determinations were performed using commercially available enzymelinked immunoassays (EIA system; Amersham Pharmacia Biotech UK, Little Chalfont, UK) with the following intra-assay and interassay coefficients of variation and detection limits, respectively: for $\mathrm{PGE}_{2}, 10 \%$, $10 \%$, and $40 \mathrm{pg} / \mathrm{ml}$; for $\mathrm{PGI}_{2}, 7 \%, 15 \%$, and $3 \mathrm{pg} / \mathrm{ml}$; for $\mathrm{TXB}_{2}, 14 \%, 10 \%$, and $3.6 \mathrm{pg} / \mathrm{ml}$. Cross-reactivities with related substances were below $0.1 \%$. The results were calculated as nanograms of prostanoid per milliliter of blood or per $10^{5}$ monocytes.

\section{Results}

\section{Change in TNF- $\alpha$ release in LPS-stimulated whole blood cultures after aspirin ingestion}

In seven of the eight tested healthy women, oral ingestion of $80 \mathrm{mg}$ aspirin induced a decrease of TNF$\alpha$ release in LPS-stimulated blood cultures $24 \mathrm{~h}$ after aspirin intake when compared with values obtained before aspirin ingestion; in one subject, TNF- $\alpha$ secretion was unaffected by aspirin intake. Figure 1 shows a marked individual variation in time course and magnitude of the aspirin-induced change in TNF- $\alpha$ release, which was observed in five out of seven blood cultures already after $12 \mathrm{~h}$ of cultivation, and in

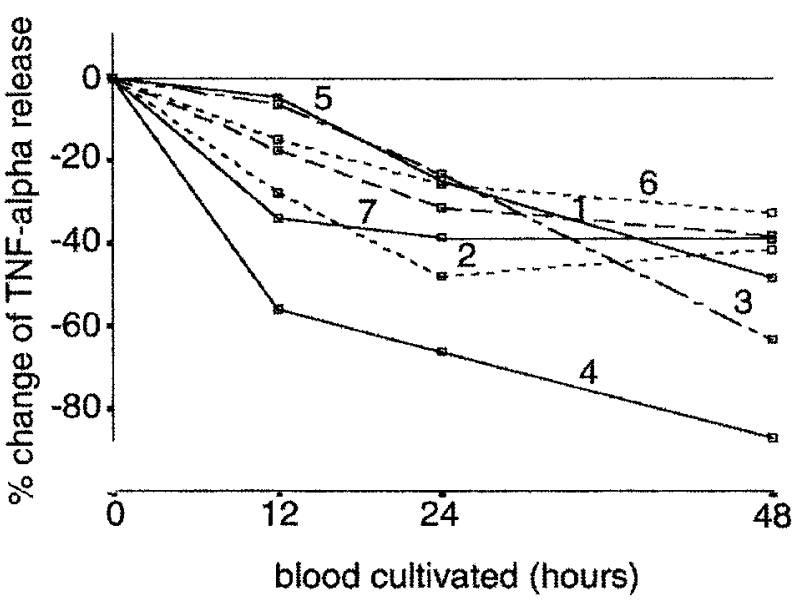

FIG. 1. Changes in tumor necrosis factor- $\alpha$ (TNF- $\alpha$ ) release in lipopolysaccharide (LPS)-stimulated blood cultures of seven healthy women $24 \mathrm{~h}$ after ingestion of $80 \mathrm{mg}$ aspirin. Venous blood, sampled immediately before and $24 \mathrm{~h}$ after oral intake of $80 \mathrm{mg}$ aspirin, was diluted 1:10 in complete RPMI and cultivated for $48 \mathrm{~h}$ in the presence of Escherichia coli O111 B4 LPS. Blood cultures were sampled at 0,12, 24 and $48 \mathrm{~h}$, and supernatants analysed by a screening line immunoassay using a single monoclonal antibody for TNF- $\alpha$ detection. The different lines (1-7) represent TNF- $\alpha$ release $24 \mathrm{~h}$ after aspirin ingestion as a percentage of values obtained before aspirin intake in seven women (subjects 1-7).

seven cases after 24 and $48 \mathrm{~h}$. The absolute values for TNF- $\alpha$ as determined for subjects $1-8$ are summarized in Table 1.

In subjects 5, 6 and 7, in whom TNF- $\alpha$ determinations were repeated with the enzyme-amplified sensitivity immunoassay, absolute TNF- $\alpha$ values differed between the two immunoassays, but the trend in aspirin-induced changes of TNF- $\alpha$ release was identical in all three subjects.

Effect of COX-2 inhibition on changes in TNF- $\alpha$ release in LPS-stimulated blood cultures after aspirin ingestion

TNF- $\alpha$ release in LPS-stimulated whole blood cultures was investigated in the presence of the specific COX-

Table 1. Tumor necrosis factor- $\alpha$ (TNF- $\alpha$ ) concentrations in blood culture supernatants after 12,24 and $48 \mathrm{~h}$ of cultivation before and $24 \mathrm{~h}$ after intake of $80 \mathrm{mg}$ aspirin in eight healthy women

\begin{tabular}{lccc}
\hline Subject number & TNF- $\alpha(\mathrm{ng} / \mathrm{ml})$ after $12 \mathrm{~h}$ & TNF- $\alpha$ (ng/ml) after 24 h \\
\hline 1 & $20.2,16.7$ & $16.7,11.5$ & $10.8,6.7$ \\
2 & $61.1,44.1$ & $57.1,29.7$ & $30.1,17.6$ \\
3 & $42.6,39.3$ & $38.3,29.5$ & $18.1,5.8$ \\
4 & $65.3,28.6$ & $37.8,12.7$ & $11.1,1.4$ \\
5 & $53.7,51.2$ & $43.6,32.8$ & $24.0,12.4$ \\
6 & $99.7,84.9$ & $72.5,53.9$ & $23.1,15.6$ \\
7 & $111.1,73.4$ & $72.7,44.6$ & $18.0,18.5$ \\
\end{tabular}

Data presented as before aspirin intake, after aspirin intake. TNF- $\alpha$ concentrations in lipopolysaccharide-stimulated blood cultures of subjects $1-8$ were determined by an enzyme-linked immunoassay (Pharmingen) and are calculated as nanograms per milliliter of blood. In all subjects, TNF- $\alpha$ concentrations at $0 \mathrm{~h}$ were below the detection limit of the assay. 


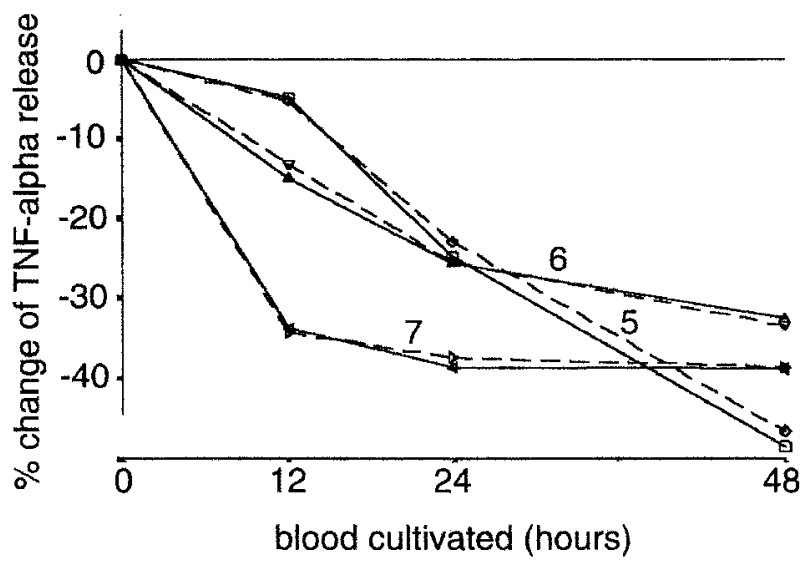

FIG. 2. Effect of cyclooxygenase-2 (COX-2) inhibition on tumor necrosis factor- $\alpha$ (TNF- $\alpha$ ) release in lipopolysaccharide (LPS)-stimulated blood cultures of three healthy women $24 \mathrm{~h}$ after ingestion of $80 \mathrm{mg}$ aspirin. For subjects 5, 6 and 7, LPS-stimulated blood cultures before and $24 \mathrm{~h}$ after aspirin intake were prepared without and with the COX-2 inhibitor DFU $(10 \mu \mathrm{M}$ in dimethylsulfoxide). TNF- $\alpha$ in culture supernatants was determined by a screening line immunoassay. The change in TNF- $\alpha$ release by aspirin intake was calculated as the percentage of values obtained before aspirin ingestion. Solid lines, change in TNF- $\alpha$ release without DFU; dashed lines, change in TNF- $\alpha$ release in the presence of DFU.

2 inhibitor, DFU, in subjects 5,6 and 7 before and after intake of $80 \mathrm{mg}$ aspirin. The maximal inhibitory dose of DFU was determined in preliminary tests (data not shown) and applied in a 10 times higher concentration in the experiments. Figure 2 shows that the presence of DFU during blood cultivation had no influence on the reduction of TNF- $\alpha$ release in blood cultures $24 \mathrm{~h}$ after aspirin intake.

Effect of aspirin intake on release of $\mathrm{PGE}_{2}, \mathrm{PGI}_{2}$ and TXA $\mathrm{T}_{2}$ in LPS-stimulated whole blood cultures

The effect of a single dose of $80 \mathrm{mg}$ aspirin on prostanoid release in LPS-stimulated whole blood cultures was investigated in the absence and presence of DFU in subjects 5,6 and 7. All three subjects showed a marked increase in $\mathrm{PGE}_{2}$ release already after $24 \mathrm{~h}$ of cultivation time, whereas this increase rose with prolonged cultivation. The effect of aspirin on release of $\mathrm{PGI}_{2}$ was less pronounced and differed individually; $\mathrm{PGI}_{2}$ secretion showed a slight increase in subjects 5 and 6 , and remained almost unchanged in subject $7 . \mathrm{TXA}_{2}$ release was almost unchanged in subject 5, and fell slightly in subjects 6 and 7 . In all three subjects, cultivation of blood in the presence of DFU reduced prostanoid production to a base level, and no effect of aspirin could be detected. In view of pronounced inter-individual differences, the results are presented for each case separately in Figure 3.
Effect of daily ingestion of $80 \mathrm{mg}$ aspirin on release of TNF- $\alpha$ and prostanoids in LPS-stimulated whole blood cultures

In an additional experiment in one woman, designed to look into the consequences of continuous intake of $80 \mathrm{mg}$ aspirin for the capacity of leukocytes to secrete TNF- $\alpha$ and prostanoids in LPS-stimulated blood cultures, subject 9 ingested aspirin for 15 consecutive days. Daily aspirin intake and preceding blood sampling were scheduled for 8.00 a.m. in order to avoid a circadian influence on cytokine secretion. ${ }^{15}$ Differential white blood cell counts (Cysmex NE 8000) performed for each blood sample showed a variation of leukocyte and leukocyte subtype numbers during the course of the experiment. Leukocytes varied between $4.9 \times 10^{6}$ and 6.1 $\times 10^{6} / \mathrm{ml}$, and monocytes between $3.7 \times 10^{5}$ and 6.8 $\times 10^{5} / \mathrm{ml}$. With the monocyte as the main source for release of TNF- $\alpha$ and prostanoids after LPS stimulation, analytical data were calculated per $10^{5}$ monocytes and compared as values per $10^{5}$ monocytes. TNF- $\alpha$ determinations were performed with the enzyme amplified sensitivity immunoassay (BioSource). Figure 4 shows the results of TNF- $\alpha$ determinations during the experiment. Daily ingestion of aspirin reduced the release of TNF- $\alpha$ in blood cultures after 12 days to a level of $48 \%$ of the value obtained before aspirin intake. In this subject, ingestion of aspirin for three more days achieved no further reduction of TNF- $\alpha$ secretion. The presence of DFU during blood cultivation did not change the results as presented in Figure 4. In subject 9, the release of all three prostanoids was reduced already after intake of one aspirin and reached a minimum after ingestion of 12 aspirin tablets, with no further reduction after intake of three more tablets. The presence of DFU in blood cultures abolished the release of prostanoids almost completely (Fig. 5).

\section{Discussion}

Preliminary experiments in unstimulated whole blood cultures of healthy individuals showed that TNF- $\alpha$ release was low, and aspirin ingestion reduced TNF- $\alpha$ levels to values below the detection level of the immunoassays. For these reasons, TNF- $\alpha$ release from leukocytes in blood cultures was stimulated with a maximal stimulating dose of $E$. coli $i$ LPS. The use of a whole blood culture model has advantages when compared with cultures of isolated monocytes or macrophages. It permits interaction between different leukocytes and between leukocytes and prostanoids released during cytokine biosynthesis, and it avoids depletion or enrichment of monocyte subpopulations during monocyte isolation or uncontrolled activation of monocytes by purification procedures. ${ }^{16}$ 


\section{subject 5}
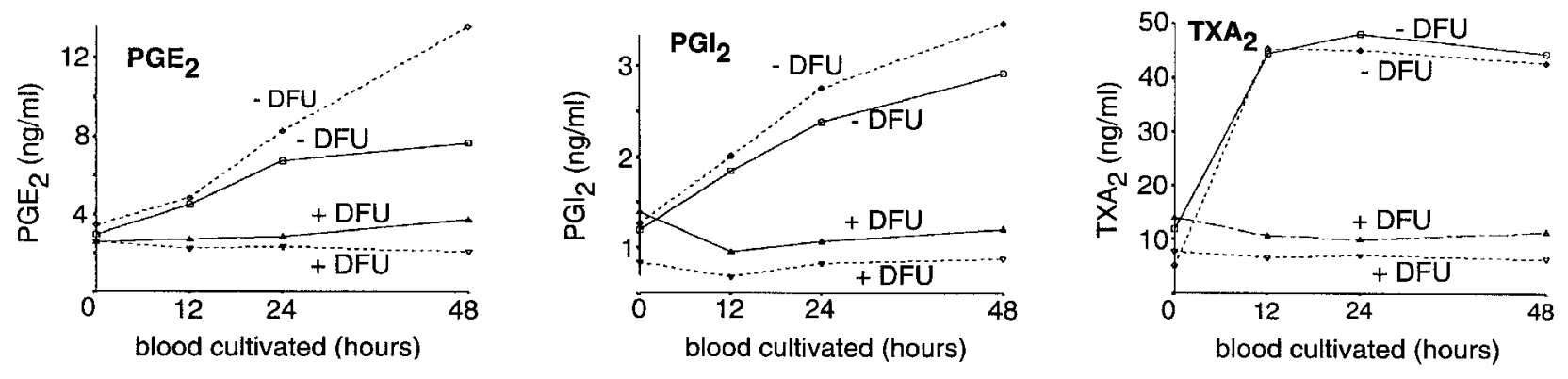

\section{subject 6}
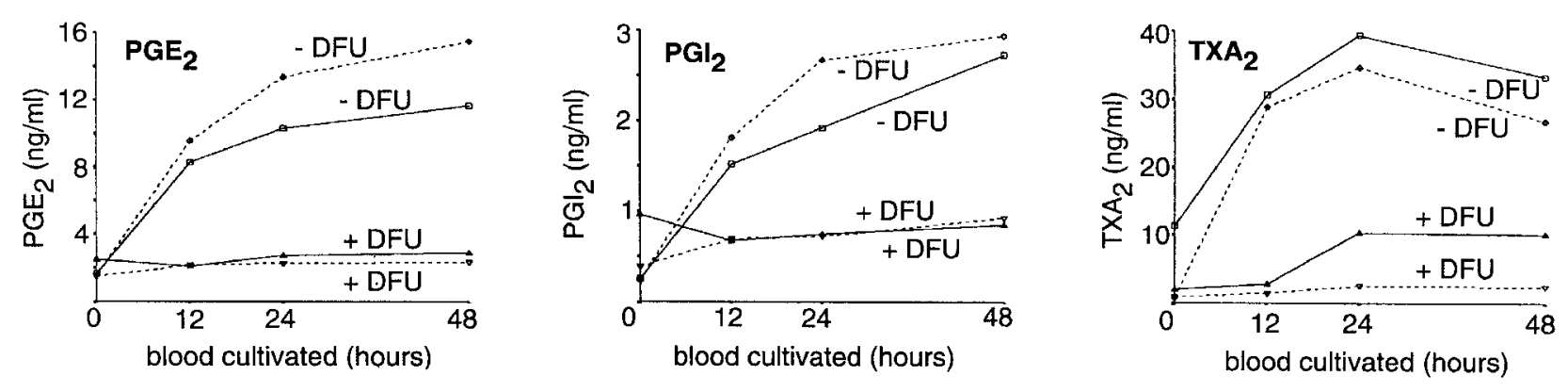

\section{subject 7}
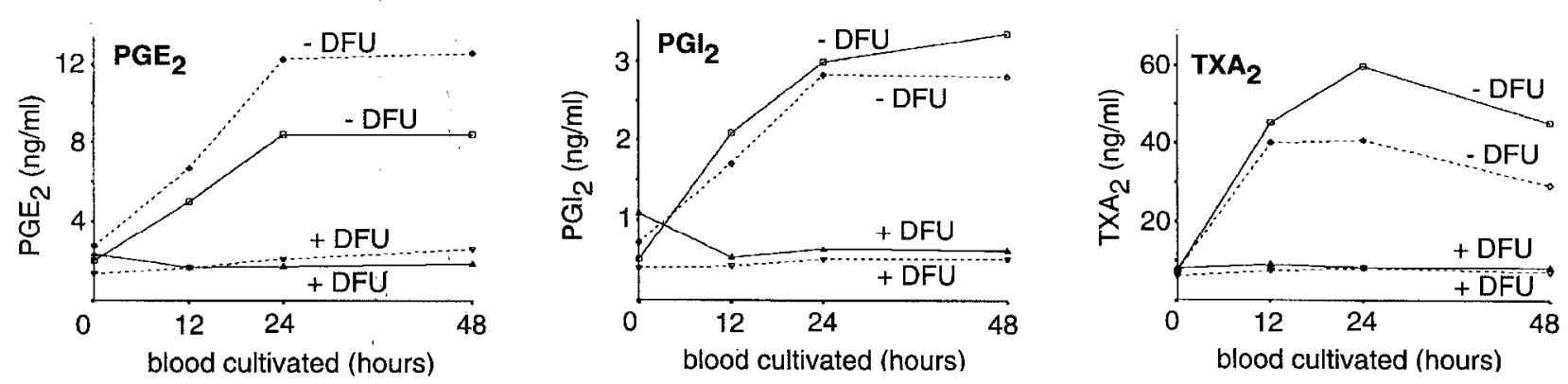

FIG. 3. The effect of ingestion of $80 \mathrm{mg}$ aspirin on the production of prostanoid $E_{2}\left(P E_{2}\right)$, prostanoid $I_{2}\left(P G I_{2}\right)$ and thromboxane $\mathrm{A}_{2}\left(\mathrm{TXA}_{2}\right)$ in lipopolysaccharide (LPS)-stimulated blood cultures, measured in the absence and presence of the cyclooxygenase-2 inhibitor DFU. LPS-stimulated blood cultures of subjects 5,6 and 7 were prepared without and with DFU (10 $\mu \mathrm{M}$ in dimethylsulfoxide) before and $24 \mathrm{~h}$ after intake of $80 \mathrm{mg}$ aspirin. Prostanoids in culture supernatants were extracted by absorption on $\mathrm{C}_{18}$-cartridges and eluation with absolute ethanol, and determined by immunoassays. Solid lines, prostanoid values $(\mathrm{ng} / \mathrm{ml})$ before aspirin intake; dashed lines, prostanoid values $(\mathrm{ng} / \mathrm{ml})$ after aspirin intake.

Although the female volunteers in our study express the known inter-individual quantitative differences in LPS-inducedTNF- $\alpha$ production, ${ }^{17,18}$ ingestion of one low dose of aspirin resulted in a reduction of TNF- $\alpha$ release by activated leukocytes in seven of eight subjects. This indicates a fundamental effect of aspirin intake on TNF- $\alpha$ biosynthesis. The observed inter-individual variability in aspirin-induced reduction of TNF- $\alpha$ release, varying from 20 to $66 \%$ at $24 \mathrm{~h}$ of blood culture, may be explained by differences in absorption, metabolism and clearance of the drug. It is questionable whether the observed reduction in TNF- $\alpha$ release in full blood cultures $24 \mathrm{~h}$ after ingestion of $80 \mathrm{mg}$ aspirin is mediated by aspirin itself. 


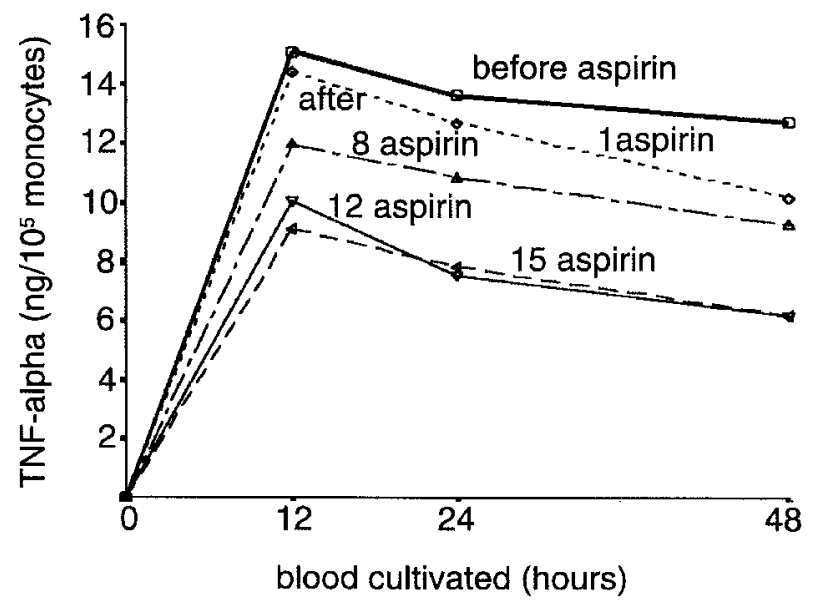

FIG. 4. The effect of a daily intake of $80 \mathrm{mg}$ aspirin on the release of tumor necrosis factor- $\alpha$ (TNF- $\alpha$ ) from lipopolysaccharide (LPS)-stimulated blood cultures from a healthy woman. Subject 9 ingested $80 \mathrm{mg}$ aspirin for 15 consecutive days. Blood was sampled immediately before aspirin intake (day 1 ) and on days 2, 9, 13 and 16. An automatic differential leukocyte count (Cysmex NE 8000) was performed in all blood samples. LPS-stimulated blood cultures were prepared, and TNF- $\alpha$ concentrations in blood culture supernatants measured by a Biosource enzyme immunoassay using three monoclonal antibodies for TNF- $\alpha$ detection and calculated as nanograms per $10^{5}$ monocytes.

Aspirin has a half-life of 20-30 min in the circulation and is deacetylated in the liver to salicylic acid. Salicylicate with a half-life of approximately $3 \mathrm{~h}$ at the usual therapeutic doses is cleared through the kidney as a glycine or glucuronic acid conjugate or metabolized to gentisic acid (2,5-dihydroxybenzoate). ${ }^{19}$ This suggests that salicylic acid and metabolites rather than acetylsalicylic acid may participate in the observed reduction of TNF- $\alpha$ release $24 \mathrm{~h}$ after aspirin ingestion. The inhibitory effect of aspirin on COX-2-induced prostaglandin biosynthesis in activated mononuclear cells is less pronounced than the blocking capacity of aspirin for constitutive COX-1, ${ }^{20}$ but aspirin and salicylate have been shown to inhibit $\mathrm{PGE}_{2}$ release from LPS-stimulated monocytes in vitro, ${ }^{21}$ as well as in vivo after oral ingestion of aspirin. ${ }^{12,13}$ In contrast to these studies, our results show an increase of $\mathrm{PGE}_{2}$ secretion in all three tested subjects after a single low dose of aspirin. The discrepancy in the effect on $\mathrm{PGE}_{2}$ release could depend on the different dosage of aspirin and salicylate applied in other studies, ${ }^{12,13}$ where doses of $300 \mathrm{mg}$ or more per day were used. The increase of $\mathrm{PGI}_{2}$ release after oral ingestion of $80 \mathrm{mg}$ aspirin in two of the three subjects in our study was less pronounced than the effect on $\mathrm{PGE}_{2}$ release, and of similar magnitude to the decrease in $\mathrm{TXA}_{2}$ secretion. Inhibition of COX-2 with the specific COX2 inhibitor DFU abolished prostanoid release almost completely, which indicates that all three prostanoids are products of LPS-induced COX-2 activity.

The three investigated prostanoids are known to affect the biosynthesis of TNF- $\alpha .^{10,11}$ The effect of
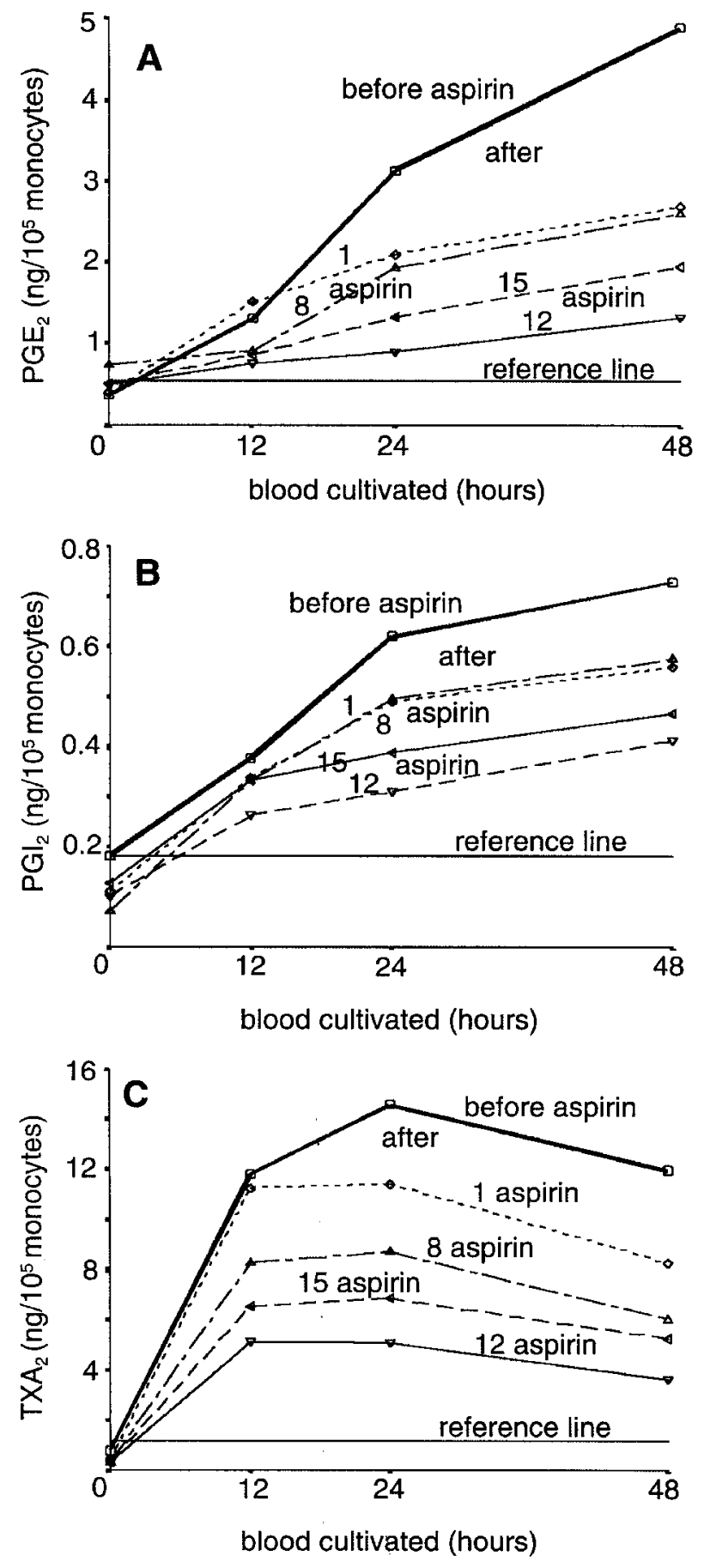

FIG. 5. The effect of a daily intake of $80 \mathrm{mg}$ aspirin on the release of prostanoids from lipopolysaccharide (LPS)-stimulated blood cultures from a healthy woman. Subject 9 ingested $80 \mathrm{mg}$ aspirin for 15 consecutive days. Blood was sampled immediately before (day 1) and after aspirin intake on days 2, 9, 13 and 16. Monocytes in blood samples were determined by differential leukocyte counting with a Cysmex NE 8000. LPS-stimulated blood cultures without and with the cyclooxygenase-2 inhibitor DFU $(10 \mu \mathrm{M}$ in dimethylsulfoxide) were prepared, prostanoids extracted from blood culture supernatants by absorption on $\mathrm{C}_{18}$ cartridges and eluation with absolute ethanol, and determined by immunoassays. Values for (A) prostanoid $E_{2}\left(P E_{2}\right)$, (B) prostanoid $\left.I_{2}\left(P_{2}\right)_{2}\right)$, and $(C)$ thromboxane $A_{2}\left(T_{X A_{2}}\right)$ were calculated as nanograms per $10^{5}$ monocytes. Concentrations of prostanoids in blood cultures with DFU were all below the indicated reference lines. 
$\mathrm{PGE}_{2}$ on TNF- $\alpha$ biosynthesis in activated monocytes is dose dependent: low concentrations of $\mathrm{PGE}_{2}$ stimulate, and higher concentrations inhibit TNF- $\alpha$ production. $^{22}$ The stable $\mathrm{PGI}_{2}$ analogs iloprost and cicaprost suppress TNF- $\alpha$ synthesis in LPS-stimulated peripheral blood mononuclear cells. ${ }^{23}$ It has been shown that $\mathrm{TXA}_{2}$ in activated monocytes functions as a paracrine or autocrine facilitator of TNF- $\alpha$ synthesis, which is at least in part determined by the balance between $\mathrm{PGE}_{2}$ and $\mathrm{TXA}_{2}$ concentrations. ${ }^{11}$ Aspirininduced changes in prostanoid concentrations could therefore affect TNF- $\alpha$ release in stimulated blood cultures. Our results show that inhibition of prostanoid biosynthesis by the specific COX-2 inhibitor DFU had no influence on the aspirin-induced reduction in TNF- $\alpha$ release, indicating that it is induced through a pathway independent of prostanoid synthesis.

The production of TNF- $\alpha$ in LPS-stimulated monocytes and macrophages is a multistep process that requires the liberation of the nuclear transcription factor $\kappa \mathrm{B}(\mathrm{NF}-\kappa \mathrm{B})^{24}$ from an inhibitory protein, IКB. Release of NF- $\kappa \mathrm{B}$ is achieved through phosphorylation and subsequent degradation of IKB by two cellular kinases, IKK- $\alpha$ and IKK- $\beta .^{25}$ Aspirin and salicylate were shown to inhibit specifically the activity of IKK- $\beta$, thus preventing the activation of NF$\kappa B$ and the NF- $\kappa B$-induced transcription of genes responsible for TNF- $\alpha$ biosynthesis. ${ }^{21,26}$ It should be noted that inhibition of IKK- $\beta$ activity by aspirin or salicylic acid in both 'in vitro' studies was achieved with concentrations equivalent to anti-inflammatory doses in vivo. Our results, showing an aspirininduced decrease in TNF- $\alpha$ release from LPS-stimulated full blood, are in agreement with these fundamental observations, but it remains questionable whether plasma levels achieved after ingestion of $80 \mathrm{mg}$ are sufficient to inhibit IKK- $\beta$ activity. Our results are contrary to the results of two studies, ${ }^{12,13}$ in which oral ingestion of aspirin increased TNF- $\alpha$ secretion from LPS-stimulated monocytes. It is possible that the higher doses of aspirin $(300$ and $325 \mathrm{mg} /$ day) that were used in these studies induce responses in mononuclear cells that are different from those obtained with low-dose aspirin. The influence of LPS concentrations during stimulation of isolated monocytes or whole blood cultures on aspirin-induced changes of TNF- $\alpha$ release was recently discussed by Osnes et al. ${ }^{27}$ Stimulation with low concentrations of LPS as used in the aforementioned studies could activate signalling pathways different from those activated by high LPS concentrations that were used in our study and by Osnes et al. in earlier experiments, ${ }^{21}$ where aspirin reduced TNF- $\alpha$ release from LPS-stimulated monocytes.

We cannot exclude the possibility that eicosanoids like 15-(R)-hydroxyeicosatetraenoic acid $(15-(R)$-HETE), produced by aspirin-acetylated COX$2^{28}$ and known to reduce TNF- $\alpha$ secretion by human monocytes, ${ }^{29}$ and lipoxygenase-mediated lipoxins participate in the observed effect of aspirin ingestion on TNF- $\alpha$ release. However, the induction of COX-2 by LPS in our experiments was initiated $24 \mathrm{~h}$ after oral low-dose aspirin intake. By this time, aspirin should be completely metabolized. ${ }^{30,31}$ Acetylated COX-1 seems to be unable to synthesize HETE-like products. ${ }^{32}$

In the single experiment with multiple intake of low-dose aspirin, the inhibition of TNF- $\alpha$ release became stable after 12 days; ingestion of three more aspirin did not further reduce $\mathrm{TNF}-\alpha$ release. The permanent reduction of TNF- $\alpha$ secretion in this experiment after continuous low-dose aspirin ingestion might be involved in the beneficial effects of the drug that were observed in pathological conditions like pre-eclampsia and FGR, where increased TNF- $\alpha$ release was detected. This requires confirmation by further experiments.

To our knowledge this is the first report of the effect of low-dose aspirin after single and multiple intake on the release of TNF- $\alpha, \mathrm{PGE}_{2}, \mathrm{PGI}_{2}$ and $\mathrm{TXA}_{2}$ in LPS-stimulated full blood cultures. Further studies with more subjects are needed to confirm and extend these first results. The question of whether salicylate and gentisic acid as metabolites of aspirin and/or lipid products of acetylated COX isoenzymes participate in the described effects on peripheral mononuclear cells remains to be answered.

\section{References}

1. Hennekens $\mathrm{CH}$. Aspirin in the treatment and prevention of cardiovascular disease. Ann Rev Public Health 1997; 18: 37-49.

2. De Gaetano G, Cerletti C. Aspirin, platelets and prevention of cardiovascular disease. J Lipid Mediat 1989; 1: 289-296.

3. Wallenburg HCS. Prevention of preeclampsia: status and perspectives Eur J Obstet Gynaecol Reprod Biol 2001; 94: 13-22.

4. Barth W. Low-dose aspirin for preeclampsia - the unresolved question. New Engl J Med 1998; 338: 756-757.

5. Leitich H, Egarter C, Husslein P, Kaider A, Schemper MA. A meta-analysis of low dose aspirin for the prevention of intrauterine growth retardation. Br J Obstet Gynaecol 1997; 104: 450-459.

6. Meldrum DR. Tumor necrosis factor in the heart. Am J Physiol 1998; 274 (3 Part 2): R577-R595.

7. Conrad KP, Benyo DF. Placental cytokines and the pathogenesis of preeclampsia. Am J Reprod Immunol 1997; 37: 240-249.

8. Heyborne KD, Witkin SS, McGregor JA. Tumor necrosis factor- $\alpha$ in midtrimester amniotic fluid is associated with impaired intrauterine fetal growth. Am J Obstet Gynecol 1992; 167: 920-925.

9. Beckmann I, Meisel-Mikolajczyk F, Lotgering FK, Wallenburg HCS. Tumor necrosis factor $\alpha$ in response to endotoxin administration in the pregnant guinea pig. Am J Obstet Gynecol 1996; 175: 218-221.

10. Ben-Efraim $S$. Interactions between macrophage cytokines and eicosanoids in expression of antitumour activity. Med Inflamm 1992; 1: 295-308

11. Caughey W, Pouliot M, Cleland LG, James MJ. Regulation of tumor necrosis factor- $\alpha$ and IL- $1 \beta$ synthesis by thromboxane $A_{2}$ in nonadherent human monocytes. J Immunol 1997; 158: 351-358.

12. Østerud B, Olsen JO, Wilgard L. Increased lipopolysaccharide-induced tissue factor activity and tumour necrosis factor production in monocytes after intake of aspirin: possible role of prostaglandin $\mathrm{E}_{2}$. Blood Coag Fibrinol 1992; 3: 309-313.

13. Endres S, Whitaker RED, Ghorbani R, Meydani SN, Dinarello CA. Oral aspirin and ibuprofen increase cytokine-induced synthesis of IL-1 $\beta$ and of tumour necrosis factor- $\alpha$ ex vivo. Immunology 1996; 87: $264-270$.

14. Riendeau D, Percival MD, Boyce S, Brideau C, Charleson S, Cromlish W, Ethier D, Evans J, Falgueyret J-P, Ford-Hutchinson AW, Gordon R, Greig G, Gresser M, Guay J, Kargman S, Léger S, Mancini JA, O'Neill G, Ouellet M, Rodger IW, Thérien M, Wang Z, Webb JK, Wong E, Xu L, Young RN, 
Zamboni R, Prasit P, Chan C-C. Biochemical and pharmacological profile of a tetrasubstituted furanone as a highly selective COX-2 inhibitor. $\mathrm{BrJ}$ Pharmacol 1997; 121: 105-117.

15. Entzian P, Linnemann K, Schlaak M, Zabel P. Obstructive sleep apnea syndrome and circadian rythms of hormones and cytokines. Am J Resp Crit Care Med 1996; 153: 1080-1086.

16. Allen JN, Herzyk DJ, Allen ED, Wewers MD. Human whole blood interleukin-1- $\beta$ production: kinetics, cell source, and comparison with TNF- $\alpha$. J Lab Clin Med 1992; 119: 538-546.

17. Westendorp RG, Langermans JAM, Huizinga TW, Elouali AH, Verweij CL, Boomsma DI, Vandenbroucke JP. Genetic influence on cytokine production and fatal meningococcal disease. Lancet 1997; 349: 170-176.

18. Endres S, Cannon JG, Ghorbani R, Dempsey RA, Sisson SD, Lonnemann G, Van der Meer JWM, Wolff SM, Dinarello CA. In vitro production of IL $1 \beta$, IL $1 \alpha$, TNF and IL 2 in healthy subjects: distribution, effect of cyclooxygenase inhibition and evidence of independent gene regulation. Eur J Immunol 1989; 19: 2327-2333.

19. Hartwig-Otto $\mathrm{H}$. Pharmacokinetic considerations of common analgesics and antipyretics. Am J Med 1983; 75: 30-37.

20. Meade EA, Smith WL, DeWitt DL. Differential inhibition of prostaglandin endoperoxide synthase (cyclooxygenase) isozymes by aspirin and other non-steroidal anti-inflammatory drugs. J Biol Chem 1993; 268: 6610-6614

21. Osnes LTN, Foss KB, Joo GB, Okkenhaug C, Westvik A-B, Øvstebo R, Kierulf $P$. Acetylsalicylic acid and sodium salicylate inhibit LPS-induced $\mathrm{NF}-\mathrm{KB} / \mathrm{c}-\mathrm{Rel}$ nuclear translocation, and synthesis of tissue factor (TF) and tumor necrosis factor alfa (TNF- $\alpha$ ) in human monocytes. Thromb Haemost 1996; 76: 970-976.

22. Renz H, Gong JH, Schmidt A, Nain M, Gemsa D. Release of tumor necrosis factor- $\alpha$ from macrophages: enhancement and suppression are dose-dependently regulated by prostaglandin $\mathrm{E}_{2}$ and cyclic nucleotides. J Immunol 1988; 141: 2388-2393.

23. Eisenhut T, Sinha B, Gröttrup-Wolfers E, Semmler J, Siess W, Endres S. Prostacyclin analogs suppress the synthesis of tumor necrosis factor- $\alpha$ in LPS-stimulated human peripheral blood mononuclear cells. Immunopharmacology 1993; 26: 259-264.
24. Lee J-I, Burckhart J. Nuclear factor kappa B: important transcription factor and therapeutic target. J Clin Pharmacol 1998; 38: 981-993.

25. Yin M-J, Yamamoto Y, Gaynor RB. The anti-inflammatory agents aspirin and salicylate inhibit the activity of ІкВ kinase- $\beta$. Nature 1998; 396 : 77-80.

26. Shakelford RE, Alford PB, Xue Y, Thai SF, Adams DO, Pizzo S. Aspirin inhibits tumor necrosis factor alpha gene expression in murine tissue macrophages. Mol Pharmacol 1997; 52: 421-429.

27. Osnes LTN, Foss Haug KB, Joø GB, Westvik A-B, Øvstebø R, Kierulf P. Aspirin potentiates LPS-induced fibrin formation (FPA) and TNF- $\alpha$-synthesis in whole blood. Thromb Haemost 2000; 83: 868-873.

28. Lecomte M, Laneuville O, Ji C, DeWitt D, Smith W. Acetylation of human prostaglandin endoperoxide synthase-2 (cyclooxygenase-2) by aspirin. $J$ Biol Chem 1994; 269: 13207-13215.

29. Ferrante JV, Huang ZH, Nandoskar M, Hii CST, Robinson BS, Rathjen DA, Poulos A, Morris CP, Ferrante A. Altered responses of human macrophages to lipopolysaccharide by hydroperoxyeicosatetraenoic acid, hydroxyeicosatetraenoic acid, and arachidonic acid. Inhibition of tumor necrosis factor production. J Clin Invest 1997; 99: 1445-1452.

30. Rymark P, Berntorp E, Nordsjö P, Liedholm H, Melander A, Gennser G. Low-dose aspirin to pregnant women: single dose pharmacokinetics and influence of short term treatment on bleeding time. J Perinat Med 1994; 22: $205-211$.

31. Benedek I, Joshi AS, Pieniaszek HJ, King S-YP, Kornhauser DM. Variability in the pharmacokinetics and pharmacodynamics of low dose aspirin in healthy male volunteers. J Clin Pharmacol 1995; 35: 1181-1186.

32. Rowlinson SW, Crews BC, Goodwin DC, Schneider C, Gierse JK, Marnett LJ. Spatial requirements for $15-(R)$-hydroxy- $5 Z, 8 Z, 11 Z, 13 E$-eicosatetraenoic acid synthesis within the cyclooxygenase active site of murine COX 2. Why acetylated COX-1 does not synthesize 15-(R)-HETE.J Biol Chem 2000; 275: 6586-6591.

\section{Received 13 February 2001;} accepted 2 March 2001 


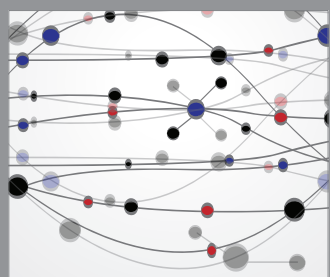

The Scientific World Journal
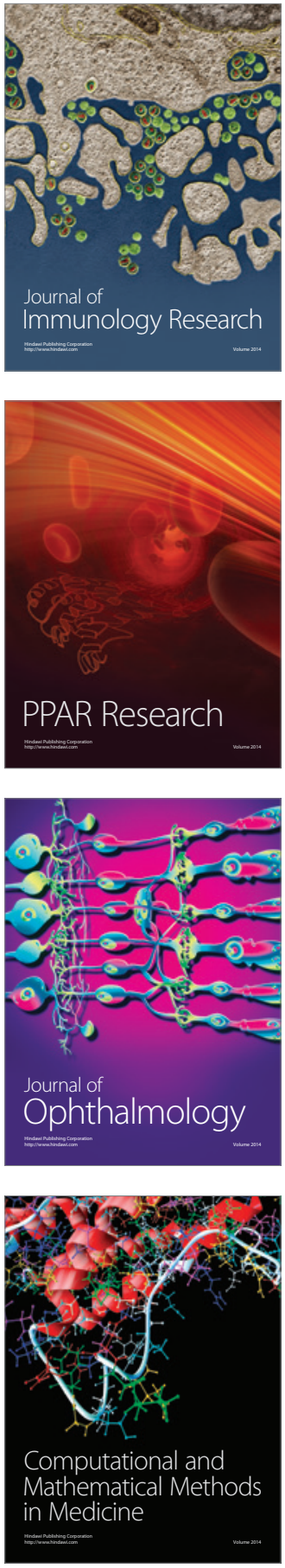

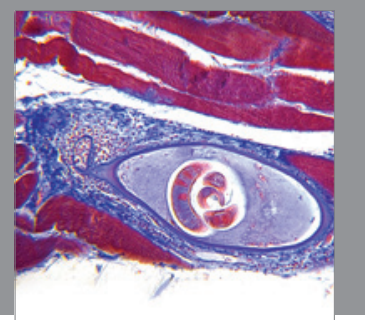

Gastroenterology

Research and Practice
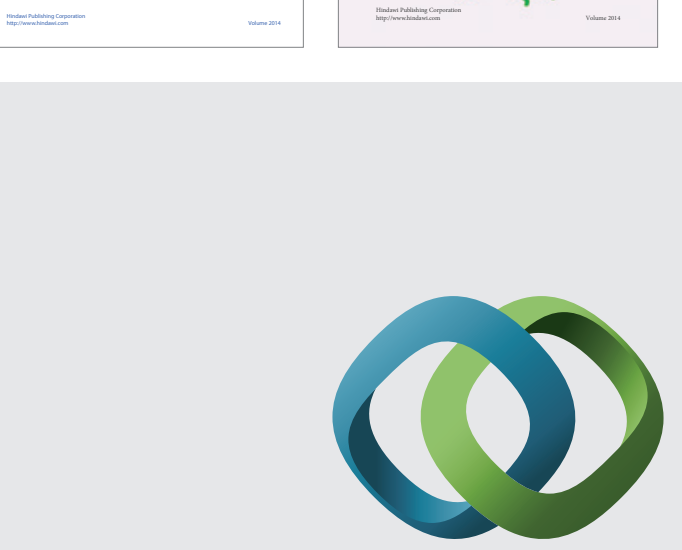

\section{Hindawi}

Submit your manuscripts at

http://www.hindawi.com
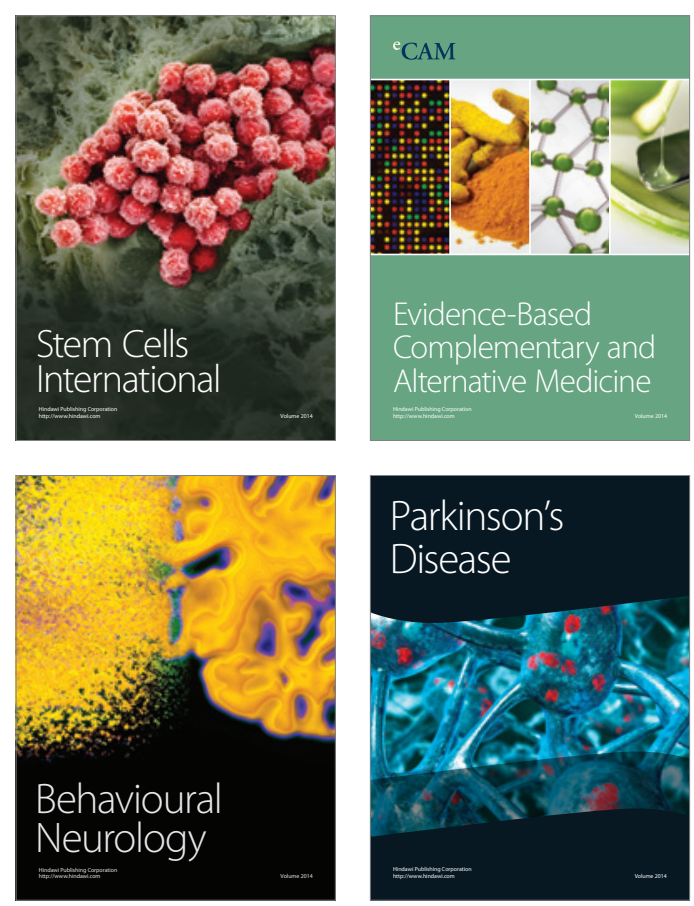

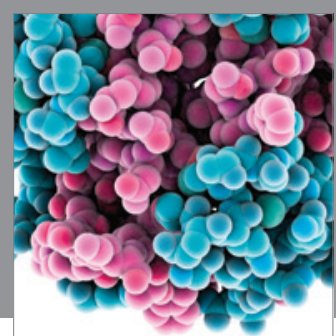

Journal of
Diabetes Research

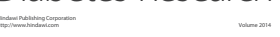

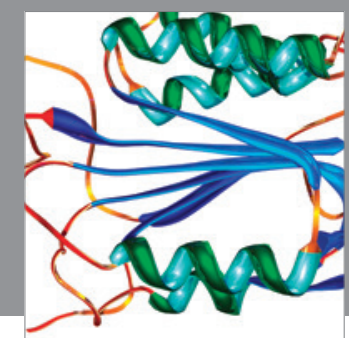

Disease Markers
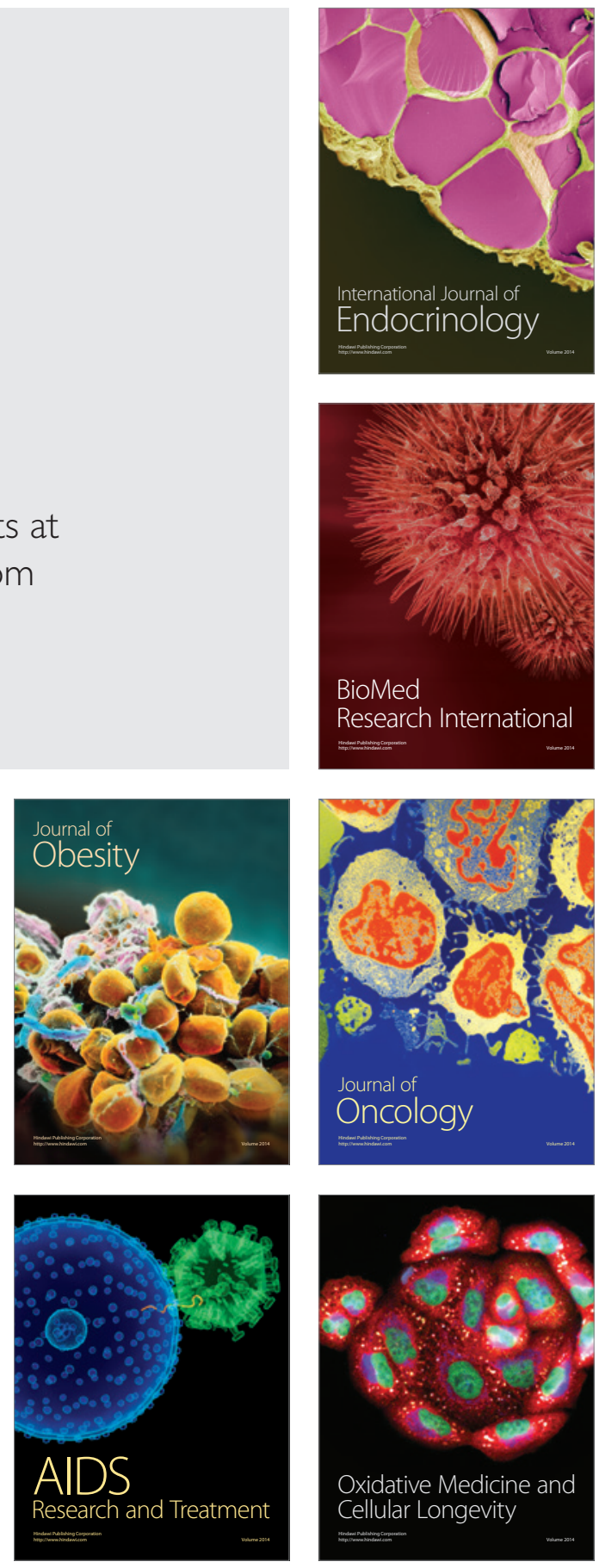